\title{
Major depressive disorder
}

\section{G Grobler}

\section{Introduction}

This treatment guideline draws on several international guidelines: $(i)$ Practice Guidelines of the American Psychiatric Association (APA) for the Treatment of Patients with Major Depressive Disorder, Second Edition; ${ }^{[1]}$ (ii) Clinical Guidelines for the Treatment of Depressive Disorders by the Canadian Psychiatric Association and the Canadian Network for Mood and Anxiety Treatments (CANMAT); ${ }^{[2]}$ (iii) National Institute for Clinical Excellence (NICE) guidelines; ${ }^{[3]}$ (iv) Royal Australian and New Zealand College of Psychiatrists Clinical Practice Guidelines Team for Depression (RANZCAP): ${ }^{[4]}(v)$ Texas Medication Algorithm Project (TMAP) Guidelines; ${ }^{[5]}$ (vi) World Federation of Societies of Biological Psychiatry (WFSBP) Treatment Guideline for Unipolar Depressive Disorder; ${ }^{[6]}$ and (vii) British Association for Psychopharmacology Guidelines. ${ }^{[7]}$

Major depressive disorder (MDD) is frequently associated with comorbid psychiatric and medical conditions and carries with it a high risk of morbidity and mortality. For many an initial episode of depression evolves into a recurrent and debilitating chronic illness with significant and pervasive impairments in psychosocial functioning. ${ }^{[8-11]}$ The recent Global Burden of Disease Study estimated that unipolar major depression is the fourth largest contributor to the global burden of disease (premature mortality and disability). ${ }^{[12]}$ By the year 2020, unipolar MDD is projected to be the second largest contributor to the global burden of disease, after heart disease. ${ }^{[13]}$

\subsection{Prevalence and risk factors}

MDD has a median lifetime prevalence of $16.1 \%$ (range $4.4-18 \%){ }^{[14]}$ Twelve-month prevalence ranges from $5 \%$ to $10 \%$ in adults, with women at higher risk than men (ratio is approximately $2: 1$ ). ${ }^{[15-17]} \mathrm{In}$ South Africa, the lifetime prevalence of MDD documented in the South African Stress and Health (SASH) survey, the first nationally representative epidemiological survey of common mental disorders in South Africa, ${ }^{[18]}$ was $9.8 \%$ across all age groups, with the highest prevalence $(14.6 \%)$ in the Free State. The survey, conducted between 2003 and 2004 was a three-stage, area probability sample of 4351 adults of all races and ethnic groups living in households and single-sex migrant labourer group quarters in South Africa. The 12 -month prevalence rate of MDD during this period was $4.9 \%$. The aforementioned SASH study found that females were 1.75 more likely to develop MDD than males.

The age of onset of MDD is difficult to assess because the first episode is frequently mild and untreated, and may be determined retrospectively many years after first onset. MDD can begin at any age, even in childhood and adolescence, but there are two peaks, in the twenties and forties. ${ }^{[1,19]}$ The mean age of onset of MDD has been estimated around the age of $30{ }^{[14]}$ Family and twin studies have indicated that MDD is a complex genetic disorder being 1.5 - 3 times more common among first-degree biological relatives of persons with this disorder than among the general population. ${ }^{[20,21]}$
Female gender, a previous episode of major depression and a positive first-degree family history of depression are the most consistently described risk factors.

\subsection{Comorbidity and consequences}

Anxiety disorders are highly comorbid, occurring in about 58\% of patients with $\mathrm{MDD}{ }^{[22]}$ In addition, anxiety symptoms are highly prevalent in MDD, occurring in up to $80 \%$ of patients. ${ }^{[23]}$ Studies investigating the effects of depression on health-related quality of life have demonstrated detrimental effects that equal or exceed those of patients with chronic medical illnesses, such as ischaemic heart disease or diabetes mellitus. ${ }^{[24-26]}$ The most serious sequela of MDD is suicide. It has been estimated that about $50 \%$ of depressed patients make at least one suicide attempt during their lifetime. ${ }^{[27]}$ It is well established that patients with mood disorders suffer a higher risk of suicide relative to the general population. ${ }^{[28]}$ However, no risk factor or classification of diagnostic subtype has been shown to reliably predict suicide. ${ }^{[29]}$ In a recent meta-analysis, the lifetime prevalence of suicide was estimated, on the basis of the intensity of the treatment setting. The analysis showed that clinically depressed patients who had been hospitalised for suicidality had a lifetime risk of suicide of $8.6 \%$. Patients with affective disorders, who had been hospitalised without specification of suicidality, had a lifetime suicide rate of $4.0 \%$. The lifetime suicide prevalence for mixed inpatient/outpatient populations was $2.2 \%$, and less than $0.5 \%$ for the non-affectively ill population. ${ }^{[2]}$ Depression also substantially increases the risk of death by cardiovascular disease. ${ }^{[30]}$

In addition to the personal suffering of individuals and their families, depression imposes significant costs on society. ${ }^{[31]}$ These include both direct total healthcare costs and indirect costs (the latter have been estimated to be much higher than direct costs). Direct costs include mental health treatment costs and all other healthcare costs. Indirect costs include such varied factors as lost productivity associated with morbidity and mortality ${ }^{[32]}$ As depression is often not properly diagnosed and/or undertreated, ${ }^{[33-36]}$ and as it can affect many individuals at a relatively early age, the impact on cost can be cumulative over time.

\section{Diagnosis and clinical characteristics}

MDD is characterised by single or recurrent major depressive episodes. The essential feature of a major depressive episode is a period of at least 2 weeks of depressed mood with abnormalities of neurovegetative functions (e.g. appetite, weight loss, sleep disturbances), psychomotor activity (e.g. loss of energy and interests, agitation or retardation), cognition (feelings of worthlessness, hopelessness or inappropriate guilt), as well as anxiety and suicidal ideation. ${ }^{[1]}$ Table 1 summarises the diagnostic criteria according to the Diagnostic and Statistical Manual of Mental Disorders, Fourth Edition, Text Revision (DSM-IV-TR $)^{[37]}$ as well as the International Statistical Classification of Diseases and Related Health Problems, Tenth Revision (ICD-10). ${ }^{[38]}$ 
Depressive symptoms and pathology lie on a spectrum in terms of duration, severity and comorbid pathology.

\subsection{Course and prognosis}

An untreated depressive episode typically lasts about 6 months or longer. ${ }^{[1,19,39]}$ Modern pharmacotherapy alleviates suffering during acute episodes, and placebo-controlled trials show response and remission occurring more quickly in actively treated groups. A 27-year prospective study of 186 unipolar depressed patients meeting DSM-III criteria for major depression found shorter episodes and cycles with increasing episode number. ${ }^{[19]}$ However, a 10 -year prospective study of 258 subjects treated for unipolar MDD showed that the duration of recurrent mood episodes remained relatively uniform over time and averaged approximately 20 weeks. ${ }^{[39}$

MDD is typically a recurrent disorder and $50-85 \%$ of the patients who have an episode will eventually have another episode. ${ }^{[40,41]}$ There is also increasing evidence that some who experience a major depressive episode will have a lifelong course of illness characterised by recurrent major depressive episodes or the development of chronicity, e.g. recurrent MDD without full inter-episodic recovery, or a chronic major depressive episode, or 'double depression' (concurrent major depression and dysthymic disorder). ${ }^{[31,42-44]}$ Between $9 \%$ and 24\% of patients with the initial diagnosis of a major depressive episode will undergo a change in diagnosis over time, mostly to bipolar disorder. ${ }^{[19,39]}$
Although the prognosis for a depressive episode is good, with most patients returning to normal functioning once the episode is over, in 20 - 30\% of cases depressive symptoms will persist. ${ }^{[40,43,45-47]}$

\section{Assessment}

A thorough diagnostic evaluation to determine both the presence of MDD and comorbid psychiatric or general medical conditions is key. This should include a review of the history of the illness including symptoms of current illness, past psychiatric and treatment history (with attention to current treatment and response to past treatment); general medical history; history of psychoactive substance abuse; personal developmental history and response to life transitions and major life events; social, occupational, and family history; mental status examination; physical examination; and laboratory investigations, as indicated.

Careful assessment of the patient's suicidal as well as homicidal risk is paramount. The APA guidelines ${ }^{[1]}$ propose evaluation of the following:

- Presence of suicidal or homicidal ideation, intent, or plans

- Access to means for suicide and the lethality of those means

- Presence of psychotic symptoms, command hallucinations in particular, or severe anxiety

- Presence of alcohol or substance use disorder(s)

- History and seriousness of previous attempts

- Family history of, or recent exposure to, suicide.

Table 1. Criteria and classification of a depressive episode and major depressive disorder ${ }^{*}$

International Classification of Diseases, Tenth Revision code ${ }^{[38]}$
A. Depressive episode
Severe (F32.2): all 3 typical symptoms plus at least 4 other common
symptoms; some severe symptoms
Moderate (F32.1): at least 2 typical symptoms plus at least 3 common
symptoms; some marked symptoms
Mild (F32.0): at least 2 typical symptoms plus at least 2 other common
symptoms; no intense symptoms

B. Recurrent depressive disorder (F33): recurrent depressive episodes

Abridged criteria of depressive episode

Minimum duration of episode: about 2 weeks

Typical symptoms

Reduced energy, increased fatigability

Loss of interest and enjoyment

Depressed mood

Other common symptoms

Diminished appetite

Disturbed sleep

Ideas or acts of self-harm or suicide

Agitation or retardation

Ideas of guilt and unworthiness

Reduced self-esteem and self confidence

Reduced concentration and attention
American Psychiatric Association's Diagnostic and Statistics Manual, Fourth Revision, Text Revision ${ }^{[37]}$

\section{Major depressive disorder \\ A. Single episode (296.2x) \\ B. Recurrent $(296.3 x)$}

Abridged criteria major depressive episode

A. Over the last 2 weeks, 5 of the following features should be present most of the day or nearly every day (must include 1 or 2 ):

Depressed mood

Loss of interest/pleasure in almost all activities

Significant weight loss/gain ( $>5 \%$ change in 1 month) or an increase or decrease in appetite nearly every day

Insomnia/hypersomnia

Psychomotor agitation or retardation (observable by others)

Fatigue or loss of energy

Feelings of worthlessness/excessive/inappropriate guilt (not merely self-reproach about being sick)

Diminished ability to think/concentrate, indecisiveness (either by subjective account or as observed by others)

Recurrent thoughts of death (not just fear of dying)/recurrent suicidal ideation/a suicide attempt/a specific plan for committing suicide

B. The symptoms cause clinically significant distress or impairment in social, occupational, or other important areas of functioning

C. Physical/organic factor or illness do not cause symptoms (e.g. drug abuse, medication, a general medical condition)

D. The symptoms are not better explained by bereavement (although this can be complicated by major depression)

*Reprinted with permission from Bauer M, Whybrow PC, Angst J, et al. World Federation of Societies of Biological Psychiatry (WFSBP) Guidelines for Biological Treatment of Unipolar Depressive Disorders, Part 1. Acute and continuation treatment of major depressive disorder. World Journal of Biological Psychiatry 2002;3:5-43. Informa Healthcare. For educational purposes only. 
Measurement-based diagnostic tools can aid in the assessment of depression severity, presence of co-occurring disorders, and suicide risk, but should always be accompanied by a clinical diagnostic assessment incorporating a differential diagnosis. ${ }^{[48]}$ Conditions that need to be excluded before making a definitive diagnosis of MDD include bipolar disorder, an adjustment disorder with depressed mood, mood disorder due to a general medical condition and a substance-induced mood disorder.

The Structured Clinical Interview for DSM-IV Axis I Disorders $(\mathrm{SCID}-\mathrm{I})^{[49]}$ and the Mini-International Neuropsychiatric Interview $(\mathrm{MINI})^{[50]}$ are clinician-rated diagnostic instruments, while the 9-item Patient Health Questionnaire (PHQ-9 ${ }^{[51]}$ and the PRIME$\mathrm{MD}^{[52]}$ are commonly used patient-rated tools. For monitoring of depressive symptoms on treatment, the Hamilton Depression Rating Scale (HAM-D) ${ }^{[53]}$ and the Montgomery-Åsberg Depression Rating Scale (MADRS) ${ }^{[54]}$ are gold-standard clinician-rated scales. Other measures include the Quick Inventory of Depressive Symptomatology (QIDS) ${ }^{[55]}$ which is available in both clinician-rated and patient-rated formats and the patient-rated Beck Depression Inventory (BDI). ${ }^{[56]}$

Diagnostic assessment and evaluation of patient safety, as well as that of others, should be followed by an evaluation of functional impairment and determination of the treatment setting (inpatient or outpatient).

\section{Treatment}

\subsection{Treatment goals}

Definitions of response, remission, and recovery ${ }^{[2]}$ are summarised in Table $2{ }^{\left[{ }^{[57]}\right.}$ In depression, full remission is defined as the virtual elimination of symptoms which in most clinical trials refers to depression scores within the normal range. This is most consistently defined as a score of 7 or less on the 17-item Hamilton Depression Rating Scale (HDRS-17). The term 'response' generally indicates a $50 \%$ reduction in depression score. Recovery from depression is often equated with remission in the literature. It is also variably defined as remission for an extended period of time or the complete absence of symptoms and improved work and psychosocial functioning.

Evidence for the benefits of treating to remission in depression is clear: remitted patients are more likely to regain full functional recovery and to suffer fewer relapses and recurrences. ${ }^{[58]}$ Remission has become the accepted treatment goal in MDD, as seen in many recent clinical trials. In the current National Institutes for Mental Health Sequenced Treatment Alternatives to Relieve Depression $\left(\mathrm{STAR}^{\star} \mathrm{D}\right)$ trial, for example, anything less than remission was viewed as treatment failure. ${ }^{[59,60]}$

\subsection{General aspects of treatment}

Treatment consists of an acute phase (during which remission of all symptoms is induced); a continuation phase, during which remission is preserved; and a maintenance phase during which susceptible patients are protected against the recurrence of subsequent major depressive episodes. ${ }^{[1]}$

\subsection{Acute treatment}

Initial management of MDD should entail: the establishment and maintenance of a therapeutic alliance; education of the patient and the family about the disorder with provision of information about treatment options; a review of the possible adverse effects of medications and potential drug-drug interactions; emphasis of the importance of taking medication as prescribed; and addressing the early signs of relapse. ${ }^{[61]}$ The appropriate treatment setting (inpatient or outpatient) should be selected and the treatment plan should be individualised to the patient's needs. ${ }^{[62]}$

Treatment decisions should also importantly take into account depression severity. A mild depressive episode, according to the $D S M-I V-T R,{ }^{[37]}$ is characterised by 5 or 6 symptoms or less and mild disability (social, occupational and other important areas of functioning), a moderate depressive episode by 6 or more symptoms and moderate disability, and a severe depressive episode by most of the symptoms (as per the DSM-IV-TR symptom list) and observable disability. According to the DSM-IV-TR, subthreshold depression comprises fewer than 5 symptoms. ${ }^{[37]}$

Guidelines differ in their opinion on the management of mild depression. The APA guidelines ${ }^{[1]}$ advise psychotherapy or antidepressant monotherapy based on patient preference. Similarly the CANMAT guidelines $^{[2]}$ recommend either cognitive-behavioural therapy (CBT), cognitive therapy, interpersonal therapy (IPT), or antidepressants as a first-line treatment, while the BAP guidelines ${ }^{[63]}$ recommend CBT, behavioural therapy with activity scheduling, IPT or an antidepressant.

For moderate depression, all guidelines accept the use of an antidepressant or evidence-based psychotherapy as a first-line choice, with the exception of the NICE guideline which recommends antidepressants as the only first-line choice. ${ }^{[3,64]}$ In view of their superior tolerability and safety, the selective serotonin reuptake inhibitors (SSRIs), serotonin-norepinephrine reuptake inhibitors (SNRIs), or the norepinephrine-dopamine reuptake inhibitors (NDRIs), and mirtazapine are encouraged over the use of the tricyclic antidepressants (TCAs) and the monoamine oxidase inhibitors (MAOIs). However, the following considerations apply in deciding on the most appropriate medication: availability, safety

Table 2. Response, remission, and recovery definitions ${ }^{[57]^{*}}$

\begin{tabular}{ll}
\hline Outcome & Definition based on Hamilton Depression Rating Scale ${ }^{[53]}$ \\
\hline Recovery & Remission and return of function \\
Remission & Response plus score of $\leq 7$ \\
Residual symptoms & Response plus score of $\geq 8$ \\
Response & $\geq 50 \%$ reduction \\
Partial response & $21-49 \%$ reduction \\
No response & $\leq 20 \%$ reduction \\
*Reprinted with permission from O’Donovan C. Achieving and sustaining remission in depression and anxiety disorders: Introduction. Canadian Journal of Psychiatry 2004;49 (Suppl 1):55-95. Canadian \\
Psychiatric Association. For educational purposes only.
\end{tabular}


and tolerability, patient preference and patient needs, and cost. ${ }^{[65]}$ Newer antidepressant classes such a melatonin agonist may also be employed. Moderate depression may necessitate a combination of both an antidepressant and psychotherapy (either CBT or IPT). The APA guidelines recommend a combination of antidepressants and psychotherapy for patients with significant psychosocial problems or Axis II disorders and/or poor compliance. ${ }^{[1]}$

For severe depression, the guidelines concur that the following firstline treatment options apply: (i) a combination of an antidepressant and psychotherapy (either CBT or IPT); (ii) electroconvulsive therapy (ECT) (6 to 10 treatments, maximum of 20, WFSBP guidelines recommend bilateral rather than unilateral ECT); or (iii) a combination of an antidepressant with an antipsychotic agent for a major depressive episode with psychotic features. ${ }^{[62]}$ In addition to using SSRIs as firstline agents, the WFSBP guidelines ${ }^{[6]}$ also recommend TCAs and SNRIs as first-line options for severe depression. The RANZCAP guidelines $^{[4]}$ suggest a TCA or venlafaxine, an SNRI, as first-line treatment with lesser evidence for use of the SSRIs as first-line therapy. The RANZCAP guidelines also recommend the use of phenelzine or CBT for depression with atypical features. The BAP guidelines ${ }^{[63]}$ do not consider psychotherapy alone as adequate for acute severe depression and recommend the use of an antidepressant as a first line. The aforementioned guidelines do not consider repetitive transcranial magnetic stimulation (rTMS), vagal nerve stimulation (VNS), hypericum extract (St John's wort) or omega 3 supplementation as first-line treatments for severe depression, but consider light therapy as first-line treatment for seasonal affective disorder (SAD).

\subsection{Pharmacological treatment}

Dosage ranges for antidepressant medications are summarised in Table $3{ }^{[1]}$ In order to improve tolerability, it may be necessary to initiate the patient on a subtherapeutic dose of an antidepressant (e.g. $10 \mathrm{mg}$ fluoxetine) with gradual titration up to therapeutic dose levels. A medication trial should be of adequate dose and duration (i.e. 8 - 12 weeks). Cognisance should be taken of pharmacodynamic and pharmacokinetic properties of the selected antidepressant, and the expectation that efficacy may only be achieved following several weeks of treatment. The principle of 'what gets you well, keeps you well' should be kept in mind.

The patient should be monitored at regular intervals (fortnightly) to assess clinical status, response, side-effects, and safety, including worsening or emergence of suicidal ideation. Response can be assessed using a measurement-based tool such as the Clinical Global Impressions Scale (CGI). In addition to monitoring response of depressive symptoms, overall change in functioning, disability and subjective well-being should also be ascertained. If side-effects are intolerable, the patient should be switched to an alternative. Mirtazapine and bupropion, for example, may be useful in patients who experience SSRI-induced sexual dysfunction.

In general benzodiazepines (which do not have specific antidepressant effects) are not recommended as monotherapy and should be used judiciously as short-term adjunctive therapy (i.e. not longer than 4 weeks) to manage symptoms of anxiety, insomnia, and agitation ${ }^{[66]}$ on an as-needed basis. Benzodiazepines should be avoided in patients with comorbid substance-use disorders.
Table 3. Dosage ranges for antidepressant medications ${ }^{[1]^{*}}$

\begin{tabular}{lll}
\hline Generic name & $\begin{array}{l}\text { Starting dosage } \\
(\mathrm{mg} / \text { day })\end{array}$ & $\begin{array}{l}\text { Usual dosage } \\
(\mathrm{mg} / \text { day })\end{array}$ \\
\hline
\end{tabular}

Tricyclics and tetracyclics

Tertiary amine tricyclics

$\begin{array}{lll}\text { Amitriptyline } & 25-50 & 100-300 \\ \text { Clomipramine } & 25 & 100-250 \\ \text { Doxepin } & 25-50 & 100-300 \\ \text { Imipramine } & 25-50 & 100-300 \\ \text { Trimipramine } & 25-50 & 100-300\end{array}$

Secondary amine tricyclics (not available in SA)

$\begin{array}{lll}\text { Desipramine } & 25-50 & 100-300 \\ \text { Nortriptyline } & 25 & 50-150 \\ \text { Protriptyline } & 10 & 15-60\end{array}$

Tetracyclics

$\begin{array}{lll}\text { Amoxapine } & 50 & 100-400 \\ \text { Maprotiline } & 50 & 100-225\end{array}$

Selective serotonin reuptake inhibitors (SSRIs)

$\begin{array}{lll}\text { Citalopram } & 20 & 20-40 \\ \text { Escitalopram } & 10 & 10-20 \\ \text { Fluoxetine } & 20 & 20-60 \\ \text { Fluvoxamine } & 50 & 50-300 \\ \text { Paroxetine } & 20 & 20-50 \\ \text { Sertraline } & 50 & 50-200\end{array}$

Dopamine-norepinephrine reuptake inhibitors (NDRIs)

$\begin{array}{lcc}\text { Bupropion } & 150 & 150-300 \\ \begin{array}{l}\text { Bupropion, sustained } \\ \text { release }\end{array} & 150 & 150-300 \\ \begin{array}{l}\text { Bupropion, extended } \\ \text { release }\end{array} & 150 & 150-300\end{array}$

Serotonin-norepinephrine reuptake inhibitors (SNRIs)

$\begin{array}{lll}\text { Duloxetine } & 40 & 40-60 \\ \text { Venlafaxine } & 37.5 & 75-375 \\ \begin{array}{l}\text { Venlafaxine, extended } \\ \text { release }\end{array} & 37.5 & 75-225\end{array}$

Serotonin modulators

$\begin{array}{lll}\text { Trazodone } & 50 & 75-400\end{array}$

Norepinephrine-serotonin modulator (NaSSA)

$\begin{array}{lll}\text { Mirtazapine } & 15 & 15-45\end{array}$

Monoamine oxidase inhibitors (MAOIs)

Irreversible, nonselective

$\begin{array}{lll}\text { Phenelzine } & 15 & 15-90 \\ \text { Tranylcypromine } & 10 & 30-60 \\ \text { Isocarboxazid } & 20 & 30-60\end{array}$

Reversible MAOI-A

$\begin{array}{lll}\text { Moclobemide } & 300 & 300-600\end{array}$

Melatonergic agonist

$\begin{array}{ll}\text { Agomelatine } & 25 \\ & 25-50\end{array}$

*Reprinted with permission from APA Practice Guideline for the Treatment of Patients with Major Depressive Disorder, 3rd ed, $\odot$ 2010). American Psychiatric Association. For educational purposes only. 


\subsection{Continuation and maintenance treatment}

According to APA guidelines, the continuation phase is defined as the 16 - 20-week period that precedes sustained and complete remission from the acute phase. To prevent relapse, antidepressant medication should be continued at the same dose used during the acute phase. The aforementioned guidelines recommend that the frequency of visits be dictated to by the patient's condition and the specific treatment. Frequency can vary from once every 2 - 3 months to a few times per week.

On average, 50 - 85\% of patients with a single episode of MDD will have at least one more episode. Therefore, following the continuation phase, maintenance phase treatment should be considered to prevent episodic recurrences. The following issues need to be borne in mind when considering maintenance treatment:

- The risk of recurrence (based on the number of previous episodes, presence of comorbid conditions, and residual symptoms between active episodes)

- The severity of episode(s) (based on the presence of suicidality, psychotic features, level of functional impairment)

- Side-effects associated with continuous treatment

- Patient preference.

The precise timing and methods of discontinuing psychotherapy and pharmacotherapy for depression have not been systematically evaluated. The decision to discontinue maintenance treatment should be based on the same factors guiding the decision to initiate maintenance treatment, including the probability of recurrence, the frequency and severity of past episodes, the persistence of depressive symptoms after recovery, the presence of comorbid disorders, and patient preference.

\subsection{Non-pharmacological treatment}

Non-pharmacological alternatives include psychotherapy (e.g. CBT, IPT) and newer alternatives that work on the basis of electric currents or magnetic impulses such as ECT, rTMS, VNS, and deep brain stimulation (DBS). Both CBT and IPT have been shown to be effective in acute depression (as monotherapy in mild depression and as augmentation in moderate and severe depression), and in preventing relapse and recurrence. ${ }^{[65]}$ ECT should be considered in patients with severe depression, in patients with depression with psychotic features, and in special circumstances or emergency situations. ${ }^{[67]}$ rTMS, VNS and DBS are not recommended as first- or second-line treatments in MDD.

\subsection{Special populations \\ 4.7.1 Subtypes}

MDD may present with melancholia, with psychotic features, with atypical features, with catatonia, or as SAD. MDD with melancholic features is characterised by anhedonia, lack of reactivity to pleasurable stimuli and typical neurovegetative features such as worsening of mood in the morning, early morning waking, and marked weight loss. ${ }^{[1]}$ Although data are inconsistent, there is some evidence that venlafaxine and TCAs may be more effective than SSRIs for this depressive subtype. As mentioned previously, depression with psychotic features responds to the addition of an antipsychotic; however ECT is also an effective first-line option. ${ }^{[6]}$
Atypical depression is characterised by mood reactivity, significantly decreased energy or leaden feelings in the limbs (leaden paralysis), heightened sensitivity to interpersonal rejection, and a reversal of neurovegetative symptoms (increased sleep and appetite). SSRIs are considered first-line agents but monoamine oxidase inhibitors (MAOIs) are also effective (the latter have demonstrated superior efficacy to the TCAs). ${ }^{[68]}$ In these patients, it is important to consider medication that has a lower propensity for sedation or weight gain or a switch to mania. SAD, a subtype characterised by autumn/ winter depressive episodes and spring/summer hypomanic episodes, responds to both antidepressants (e.g. SSRIs) and light therapy. Both of the aforementioned treatments may be used as first-line, either separately or in combination. ${ }^{[69]}$ The extended release formulation of bupropion is US Food and Drug Administration (FDA)-approved for use in patients with this subtype (i.e. seasonal MDD). In patients with catatonia, ECT has been shown to be effective. ${ }^{[70]}$ Intravenous administration with a benzodiazepine (e.g. lorazepam, diazepam) may also induce rapid relief. ${ }^{[1]}$

\subsubsection{Comorbidity}

Patients with coexisting dysthymic disorder usually have a better response to a combination of an antidepressant and psychotherapy than to either treatment alone. In patients with comorbid anxiety disorders, SSRIs or SNRIs are a good first choice. ${ }^{[72]}$ In addition, shortterm augmentation with a benzodiazepine may be warranted and may also assist in enhancing compliance. In patients with comorbid panic disorder, it is prudent to start off with lower dose of an SSRI; in patients with comorbid obsessive-compulsive disorder (OCD) a serotonergic agent (SSRI or clomipramine) is advised; and in patients with comorbid social anxiety disorder, an SSRI or venlafaxine but not a TCA should be used. ${ }^{[73,74]}$ Psychotherapies such as CBT, behavioural therapy, and IPT may also be used to treat anxiety disorders and symptoms in this setting. Substance use disorders are often comorbid with MDD and in these patients an SSRI would be a good option although it may be necessary to detoxify these patients and then treat the substance use disorder first. For patients with comorbid borderline personality disorder, an SSRI or SNRI, should be considered. The behavioural impulsivity and dyscontrol can also be treated with a lowdose antipsychotic, lithium, or an antiepileptic medication. ${ }^{[75]}$

In patients with comorbid medical disorders, the choice of antidepressant medication and the potential for multiple interactions with other medications need careful consideration; for example, in patients with cardiac disease TCAs should be avoided while in patients with stroke or epilepsy an SSRI is preferred. ${ }^{[76]}$ In HIV-infected patients, SSRIs are a preferred choice and are better tolerated than TCAs. For those patients on antiretroviral treatment, it is important to check for potential drug-drug interactions when choosing an antidepressant. ${ }^{[77]}$

\subsubsection{Suicidality}

Debate about the risks of suicidal ideation and attempts following the initiation of antidepressant treatment continues. It is well known that as mood begins to improve on antidepressant treatment, so too do neurovegetative symptoms, energy and psychomotor activity. Patients may, therefore, act on pre-existing suicidal intent. ${ }^{[78]}$ Recent meta-analyses of data from clinical trials have shown a statistically 
significant increase in suicidal thoughts or behaviours in depressed individuals aged 25 years or younger treated with antidepressant medications, compared with placebo, with a 1.5- to 2.5-fold increase in the relative risk. ${ }^{[79,80]}$ In contrast, no change in risk was detected for adults aged 25 to 64 years, while older adults (aged 65 years or older) on antidepressant treatment showed a decrease in the risk of suicidal thinking or behaviours. All antidepressants, in accordance with an FDA directive, carry a black-box warning that advises of the increased risk of suicidal thinking and behaviour pertaining to children, adolescents, and young adults. ${ }^{[81]}$

\subsubsection{Pregnancy and lactation}

Both antidepressant use and untreated depression in pregnancy carry their own set of risks. Any decision to commence, continue, or discontinue an antidepressant needs to weigh up the risks and the benefits to mother and infant. Furthermore, it is important to bear in mind that relapse rates for women with a history of MDD are high during pregnancy, especially when antidepressants are discontinued. ${ }^{[82]}$

The risk of teratogenicity with antidepressants following firsttrimester exposure appears to be low overall. However, some rare birth defects have been observed to occur at higher rates with the use of specific SSRIs. For example first-trimester paroxetine exposure has been associated with cardiac malformations, a finding that resulted in changes in FDA labelling for paroxetine. Although most earlier reports ${ }^{[83]}$ suggested that SSRIs were not associated with a greater risk of congenital malformation, Chambers et al. ${ }^{[84]}$ have since shown that SSRIs can adversely affect fetal development. Antidepressant use in late pregnancy has been shown in some, but not all, studies to result in medical complications such as prematurity and transient neonatal withdrawal/adaptation syndrome.

ECT is both safe and effective during pregnancy and should be considered in pregnant women with moderate to severe depression who are unresponsive to, or unsuitable for, pharmacotherapy, for pregnant patients with psychotic features, and for pregnant patients who prefer this modality. MDD with postpartum onset is defined, in the DSM-IV-TR, as a major depressive episode with onset within 4 weeks of delivery. Antidepressants can be prescribed for postpartum depression, in accordance with the same treatment principles delineated for other types of MDD. ${ }^{[85]}$

While long-term evidence on the risks and benefits of antidepressant use during lactation are as yet not available, existing data suggest that antidepressants are compatible with breastfeeding. There have been case reports of adverse effects in breastfeeding infants exposed to maternal antidepressants but most studies have indicated low levels of exposure via breast milk with the SSRIs. The exception to this is fluoxetine, which appears to have a dose-related risk for detectable levels in infant sera. ${ }^{[86]}$

\subsection{Managing partial and non-response}

Medication response may take 6 - 8 weeks or longer. If a first-line treatment has not worked after 8 weeks at an optimal dose (i.e. there is no response), most guidelines recommend a re-evaluation of symptoms and adverse effects before switching to another antidepressant from another class; for example, if a patient has had a trial of an SSRI then one should consider switching to an SNRI or to mirtazapine or bupropion. ${ }^{[87]}$
If a first-line treatment has partially worked (i.e. there is a partial response), then it is important to ensure that the patient is adherent and not experiencing intolerable side-effects. In this instance, the dose should be increased. If there is still no response after 4 - 6 weeks, it is prudent to consider combining the existing antidepressant with another antidepressant with a different mechanism of action (e.g. combining bupropion or mirtazapine with an SSRI, combining an SSRI with a TCA, combining venlafaxine with mirtazapine). Alternatively, augmentation strategies can be tried. These include the addition of lithium, an atypical antipsychotic, triiodothyronine (T3) or mianserin. ${ }^{[88]}$

\section{Summary points}

- First-line treatment for mild to moderate depression should consist of psychotherapy (CBT or IPT) either alone or in combination with an SSRI, an SNRI (e.g. venlafaxine), bupropion, mirtazapine or agomelatine.

- For severe depression, always consider an antidepressant as firstline (an SSRI, venlafaxine (SNRI), bupropion or mirtazapine) in combination with CBT or IPT, or alternatively consider ECT.

- Severe major depression with psychotic features warrants a combination of an antidepressant with an antipsychotic. ECT should also be considered. Consider a combination of either a tertiary amine tricyclic antidepressant with an antipsychotic agent (either a first- or second-generation antipsychotic); an SSRI in combination with an antipsychotic; or venlafaxine in combination with an antipsychotic.

- Choice of medication should be based on patient profile, sideeffect profile, medication availability, nature of prior response to medication, comorbid psychiatric and medical conditions, patient preference, potential drug interactions and cost.

- If a patient presents without comorbidities and has had a previous satisfactory response to an SSRI, consider initiating treatment with a SSRI. If a patient presents with a comorbid anxiety or pain disorder, consider initiating treatment with an SSRI, SNRI or mirtazapine.

- Monitor patients initially at least fortnightly and continue medication treatment for 4 - 6 weeks.

- If remission is achieved, continuation treatment is warranted.

- With partial responders but not full remitters, increase the dose and continue for a further 4 - 6 weeks and reassess.

- With no response, choose to: (i) switch to another first-line medication from a different pharmaceutical class; (ii) augment with any one of the following: lithium, triiodothyronine (T3), an antipsychotic agent, an anticonvulsant/mood stabiliser; or (iii) combine an SSRI with a TCA, an SSRI with bupropion, an SSRI with mirtazapine, or venlafaxine with mirtazapine.

\section{References}

1. American Psychiatric Association. Practice Guideline for the Treatment of Patients With Major Depressive Disorder, 2nd ed. Am J Psychiatry 2000;157:1-45.

2. Canadian Psychiatric Association. Canadian Network for Mood and Anxiety Treatments (CANMAT). Clinical guidelines for the treatment of depressive disorders. Can J Psychiatry 2001;46(Suppl 1):5S-90S.

3. National Institute for Health and Clinical Excellence. Depression: the Treatment and Management of Depression in Adults. 2009. http://www.nice.org.uk/CG90. (accessed 6 August 2013).

4. Royal Australian and New Zealand College of Psychiatrists, Clinical Practice Guidelines Team for Depression. Australian and New Zealand Clinical Practice Guidelines for the Treatment of Depression. Aust N Z J Psychiatry 2004;38:389-407.

5. Suehs BT, Argo TR, Bendele SD, et al. Texas Medication Algorithm Project Procedural Manual: Major Depressive Disorder Algorithms. 2008. Austin: Texas Department of State Health Services http://www. dshs.state.tx.us/mhprograms/disclaimer.shtm (accessed August 2013).

6. Bauer M, Bschor T, Pfennig A, et al, for the WFSBP Task Force on Unipolar Depressive Disorders. World
Federation of Societies of Biological Psychiatry (WFSBP) Guidelines for biological treatment of unipolar depressive disorders in primary care. World Journal of Biological Psychiatry 2007;8:67-104. 
7. Anderson IM, Ferrier IN, Baldwin RC, et al. Evidence-based guidelines for treating depressive disorder with antidepressants: A revision of the 2000 British Association for Psychopharmacology guidelines. I Psychopharmacol 2008;22:343-396.[http://dx.doi.org/1177/0269881107088441]

8. Klerman GL, Weissman MM. The course, morbidity, and costs of depression. Arch Gen Psychiatry 1992;49:831-834.

9. Mintz J, Mintz LI, Arruda MI, Hwang SS. Treatments of depression and functional capacity to work Arch Gen Psychiatry 1992;49:761-768.

10. Judd LL, Akiskal HS, Zeller PJ, et al. Psychosocial disability during the long-term course of unipola major depressive disorder. Arch Gen Psychiatry 2000;57:375-380

11. Hirschfeld RM, Montgomery SA, Keller MB, et al. Social functioning in depression: a review. J Clin Psychiatry 2000;61:268-275.

12. Murray CJL, Lopez AD. Global mortality, disability, and the contribution of risk factors: Global Burden of Disease Study. Lancet 1997;349:1436-1442.

13. Murray CJL, Lopez AD. Alternative projections of mortality and disability by cause 1990-2020: Globa Burden of Disease Study. Lancet 1997;349:1498-1504.

14. Wittchen HU. Epidemiology of affective disorders. In: Helmchen H, Henn F, Lauter H, Sartorius N, eds. Contemporary Psychiatry, Vol. 3. Heidelberg: Springer, 2000:231-241.

15. Regier DA, Narrow WE, Rae DS, et al. The de facto US mental and addictive disorders service system. Epidemiologic catchment area prospective 1-year prevalence rates of disorders and services. Arch Gen Psychiatry 1993:50:85-94.

16. Kessler RC, McGonagle KA, Zhao S, et al. Lifetime and 12-month prevalence of DSM-III-R psychiatri disorders in the United States. Arch Gen Psychiatry 1994;51:8-19.

17. Picinelli M, Gomez Homen F. Gender differences in the epidemiology of affective disorders and schizophrenia. Geneva: World Health Organization, 1997.

18. Williams DR, Herman A, Stein DJ, et al. Twelve-month mental disorders in South Africa: prevalence, service use and demographic correlates in the population-based South African Stress and Health Study. Psychol Med 2008;38:211-220

19. Angst J, Preisig M. Course of a clinical cohort of unipolar, bipolar and schizoaffective patients. Results of a prospective study from 1959 to 1985. Schweizer Archiv fur Neurologie und Psychiatrie 1995;146:5-16.

20. Maier W, Gaensicke M, Freyberger HJ, et al. Generalized anxiety disorder (ICD-10) in primary care from a cross-cultural perspective: A valid diagnostic entity? Acta Psychiatr Scand 2000;101:29-36.

21. Sullivan PF, Neale MC, Kendler KS. Genetic epidemiology of major depression: Review and metaanalysis. Am J Psychiatry 2000;157:1552-1562.

22. Melartin T, Rytsala H, Leskela U, et al. Current comorbidity of psychiatric disorders among DSM-IV major depressive disorder patients in psychiatric care in the Vantaa Depression Study. J Clin Psychiatry 2002;63:126-134.

23. Zimmerman M, Chelminski I, McDermut W. Major depressive disorder and axis I diagnostic comorbidity. J Clin Psychiatry 2002:63:187-193.

24. Wells KB, Stewart A, Hays RD, et al. The functioning and well-being of depressed patients. Results from the Medical Outcomes Study. JAMA 1989;262:914-919.

25. Agency for Health Care Policy and Research (AHCPR). Evidence Report on Treatment of Depression: Newer Pharmacotherapies. San Antonio Evidence-Based Practice Center. Washington, DC: AHCPR, Evidence-Based Practice Centers, 1999,AHCPR pub. No. 99-E014.

26. Unützer J, Patrick DL, Diehr P, et al. Quality adjusted life years in older adults with depressive symptom and chronic medical disorders. Int Psychogeriatr 2000;12:15-33.

27. Rihmer Z. Suicide and bipolar disorder. In: Zarate CA, Manji HK, eds. Bipolar Depression: Molecula Neurobiology, Clinical Diagnosis and Pharmacotherapy. Basel: Birkhauser Verlag, 2009:47-56.

28. Angst J. Suicide risk in patients with major depressive disorder. J Clin Psychiatry 1999;60(Suppl 2):57-62

29. Bostwick JM, Pankratz VS. Affective disorders and suicide risk: A reexamination. Am J Psychiatry 2000;157:1925-1932

30. Wulsin LR, Vaillant GE, Wells VE. A systematic review of the mortality of depression. Psychosom Me 1999;61:6-17.

31. Brunello N, Burrows GD, Jönsson CPB, et al. Critical issues in the treatment of affective disorders Depression 1995;3:187-198

32. Booth BM, Zang M, Rost KM, et al. Measuring outcomes and costs for major depression. Psychopharmacology Bulletin 1997;33:653-658

33. Wells KB, Hays RD, Burnam MA, et al. Detection of depressive disorder for patients receiving prepaid o fee-for service care. Results from the Medical Outcomes Study. JAMA 1989;262:3298-3302.

34. Üstün TB, Sartorius N. Mental Illness in General Health Care: An International Study. Chichester Wiley 1995.

35. Unützer J, Simon G, Belin TR, et al. Care for depression in HMO patients aged 65 and older. J An Geriatr Soc 2000:48:871-878.

36. Young AS, Klap R, Sherbourne CD, Wells KB. The quality of care for depressive and anxiety disorders in the United States. Arch Gen Psychiatry 2001;58:55-61.

37. American Psychiatric Association. Diagnostic and Statistical Manual of Mental Disorders, Fourth Edition, Text Revision (DSM-IV-TR). Washington, DC. American Psychiatric Association, 2000.

38. World Health Organization. Manual of the International Statistical Classification of Diseases, Injuries and Causes of Death, Tenth Revision. Geneva: World Health Organization, 1992.

39. Solomon DA, Keller MB, Leon AC, et al. Recovery from major depression. A 10-year prospective followup across multiple episodes. Arch Gen Psychiatry 1997;54:1001-1006.

40. Keller MB, Lavori PW, Rice J, et al. The persistent risk of chronicity in recurrent episodes of nonbipola major depressive disorder: A prospective follow up. Am J Psychiatry 1986;143:24-28.

41. Mueller TI, Leon AC, Keller MB, et al. Recurrence after recovery from major depressive disorder durin 15 years of observational follow-up. Am J Psychiatry 1999;156:1000-1006.

42. Angst J. Major depression in 1998: Are we providing optimal therapy? J Clin Psychiatry 1999:60(Supp 6):5-9.

43. Judd LL, Akiskal HS, Maser JD, et al. A prospective 12-year study of subsyndromal and syndroma depressive symptoms in unipolar major depressive disorders. Arch Gen Psychiatry 1998:55:694-700.

44. Judd LL, Paulus MJ, Schettler PJ, et al. Does incomplete recovery from first lifetime major depressive episode herald a chronic course of illness? Am J Psychiatry 2000;157:1501-1504.

45. Angst J. The course of affective disorders. Psychopathology 1986;19(Suppl 2):47-52

46. Scott J. Chronic depression. Br J Psychiatry 1988;153:287-297.

47. Paykel ES. Epidemiology of refractory depression. In: Nolen WA, Zohar J, Roose SP, Amsterdam JD, eds. Refractory Depression: Current Sstrategies and Future Directions. Chichester: Wiley,1994:3-17.

48. Gelenberg AJ. Using assessment tools to screen for, diagnose, and treat major depressive disorder in clinical practice. J Clin Psychiatry 2010;71(Suppl E1):e01. [http://dx.doi.org/10.4088/ JCP.9058selc.01gry]
49. First MB, Spitzer RL, Gibbon M, Williams JBW. Structured clinical interview for DSM-IV-TR Axis I disorders, Research Version, Non-patient Edition (SCID-I/NP). New York: Biometric Research, New York State Psychiatric Institute, 2002.

50. Sheehan DV, Lecrubier Y, Sheehan KH, et al. The Mini-International Neuropsychiatric Interview (M.I.N.I.): The development and validation of a structured diagnostic psychiatric interview for DSM-IV and ICD-10. J Clin Psychiatry 1998;59(Suppl 20):22-33.

51. Kroenke K, Spitzer R, et al. The PHQ-9: Validity of a brief depression symptom severity measure. Gen Intern Med 2001;16:606-613

52. Spitzer RL, Williams JBW, Kroenke K, et al. Utility of a new procedure for diagnosing menta disorders in primary care: the PRIME-MD 1000 Study. JAMA 1994;272:1749-1756.

53. Hamilton M. A rating scale for depression. J Neurol Neurosurg Psychiatry 1960;23:56-62.

54. Montgomery SA, Asberg M. A new depression scale designed to be sensitive to change. Br Psychiatry 1979;134:382-389.

55. Rush AJ, Trivedi MH, Ibrahim HM, et al. The 16-Item Quick Inventory of Depressive Symptomatology (QIDS), clinician rating (QIDS-C), and self-report (QIDS-SR): A psychometric evaluation in patients with chronic major depression. Biol Psychiatry 2003;54:573-583.

56. Beck AT, Ward $\mathrm{CH}$, Mendelson M, et al. An inventory for measuring depression. Arch Gen Psychiatry 1961;4:561-571.

57. O'Donovan C. Achieving and sustaining remission in depression and anxiety disorders: Introduction. Can J Psychiatry 2004;49 (Suppl 1):5S-9S.

58. Judd L, Schettler P, Akiskal H. The prevalence, clinical relevance, and public health significance of subthreshold depressions. Psychiatr Clin North Am 2002;25:685-698.

59. Parikh S, Lam R. Clinical guidelines for the treatment of depressive disorders, I. Definitions, prevalence, and health burden. Can J Psychiatry 2001:46(Suppl 1):13S-20S.

60. National Institute of Mental Health. Sequenced Treatment Alternatives to Relieve Depression 2002. Bethesda, MD: National Institute of Mental Health, 2002. http://www.edc.gsph.pitt.edu/ stard/public/index.html-ssi.

61. Nutt D. Treatment of depression and concomitant anxiety. Eur Neuropsychopharmaco 2000;10(Suppl 4):S433-437

62. Davidson JRT. Major depressive disorder treatment guidelines in America and Europe. J Clin Psychiatry 2010;71(Suppl E):e04.

63. Anderson IM, Nutt DJ, Deakin JF. Evidence-based guidelines for treating depressive disorder with antidepressants: A revision of the 1993 British Association for Psychopharmacology Guidelines. J Psychopharmacol 2000;14:3-20.

64. Baldwin R, Wild R. Management of depression in later life. Advances in Psychiatric Treatment 2004;10:131-139. [http://dx.doi.org/10.1192/apt.10.2.131]

65. Nutt DJ, Davidson JR, Gelenberg AJ, et al. International consensus statement on major depressive disorder. J Clin Psychiatry 2010;71(Suppl E1):e08. [http://dx.doi.org/10.4088/JCP.9058selc.08gry]

66. Birkenhager TK, Moleman P, Nolen WA. Benzodiazepines for depression? A review of the literature Int Clin Psychopharmacol 1995;10:181-195.

67. Nemeroff CB, Heim CM, Thase ME, et al. Differential responses to psychotherapy versus pharmacotherapy in patients with chronic forms of major depression and childhood trauma. Proc Natl Acad Sci U S A 2003;100:14293-14296.

68. Pae C-U, Tharwani H, Marks DM, et al. Atypical Depression: A Comprehensive Review. CNS Drugs 2009;23:1023-1037.

69. Westrin A, Lam RW. Seasonal affective disorder: A clinical update. Ann Clin Psychiatry 2007;19:239-246.

70. Young JL, Rund D. Psychiatric considerations in patients with decreased levels of consciousness. Emerg Med Clin North Am 2010;28:595-609.

71. Bush G, Fink M, Petrides G, et al. Catatonia II. Treatment with lorazepam and electroconvulsive therapy. Acta Psychiatr Scand 1996;93:137-143.

72. Montgomery Sa, Judge R. Treatment of depression with associated anxiety: Comparisons of tricyclic antidepressants and selective serotonin reuptake inhibitors. Acta Psychiatr Scand 2000;403:9-16.

73. Schneier FR, Blanco C, Campeas R, et al. Citalopram treatment of social anxiety disorder with comorbid major depression. Depress Anxiety 2003;17:191-196.

74. Jefferson JW. Social Anxiety Disorder: More than just a little shyness. Primary Care Companion to J Clin Psychiatry 2001;3:4-9.

75. American Psychiatric Association. Practice guideline for the treatment of patients with borderline personality disorder. Am J Psychiatry 2001;158:1-52.

76. Levenson JL. Depression in the medically ill. Primary Psychiatry 2005;12:22-24.

77. Yanofski J, Croarkin P. Choosing antidepressants for HIV and AIDS patients: Insights on safety and side effects. Psychiatry 2008;5:61-66

78. Teicher MH, Glod CA, Cole JO.Antidepressant drugs and the emergence of suicidal tendencies Drug Safety 1993;8:186-212.

79. Hammad TA. Review and evaluation of clinical data. Washington, DC: Food and Drug Administration, 2004. http://www.fda.gov/ohrms/dockets/ac/04/briefing/2004-4065b1-10Administration, 2004. http

80. Hammad TA, Laughren T, Racoosin J. Suicidality in pediatric patients treated with antidepressan drugs. Arch Gen Psychiatry 2006;63:332-339.

81. Gibbons RD, Brown CH, Hur K, et al. Relationship between antidepressants and suicide attempts: An analysis of the veterans health administration data sets. Am J Psychiatry 2007;164:1044-1049.

82. Kalra S, Born L, Sarkar M, Einarson A. The safety of antidepressant use in pregnancy. Exp Opin Drug Saf 2005;4:273-284

83. Eberhard-Gran M, Eskild A, Opjordsmoen S. Treating mood disorders during pregnancy: Safety considerations. Drug Saf 2005;28:695-706.

84. Chambers CD, Hernandez-Diaz S, Van Marter LJ, et al. Selective serotonin-reuptake inhibitor and risk of persistent pulmonary hypertension of the newborn. New Engl J Med 2006;354:579 587

85. Wisner KL, Parry BL, Piontek CM. Postpartum depression. New Engl J Med 2002;347:194-199.

86. Kohen D. Psychotropic medication and breast-feeding. Advances in Psychiatric Treatmen 2005; 11:371-379

87. Hirschfeld RMA, Montgomery SA, Aguglia E, et al. Partial response and nonresponse to antidepressant therapy: Current approaches and treatment options. J Clin Psychiatry 2002;63:826-837

88. Fava M, Rush AJ. Current status of augmentation and combination treatments for majo depressive disorder: A literature review and a proposal for a novel approach to improve practice. Psychother Psychosom 2006;75:139-153. 